Chapman University

Chapman University Digital Commons

Food Science Faculty Articles and Research

Science and Technology Faculty Articles and

Research

$11-16-2017$

\title{
Use of Enzyme-Linked Immunosorbent Assay to Screen for Aflatoxins, Ochratoxin A, and Deoxynivalenol in Dry Pet Foods
}

Tara A. Okuma

Chapman University

Thu P. Huynh

Helica Biosystems, Inc.

Rosalee S. Hellberg

Chapman University, hellberg@chapman.edu

Follow this and additional works at: https://digitalcommons.chapman.edu/food_science_articles

Part of the Food Chemistry Commons, and the Other Food Science Commons

\section{Recommended Citation}

Okuma, T.A., Huynh, T.P. \& Hellberg, R.S. Mycotoxin Res (2018) 34: 69. https://doi.org/10.1007/s12550-017-0300-3

This Article is brought to you for free and open access by the Science and Technology Faculty Articles and Research at Chapman University Digital Commons. It has been accepted for inclusion in Food Science Faculty Articles and Research by an authorized administrator of Chapman University Digital Commons. For more information, please contact laughtin@chapman.edu. 


\section{Use of Enzyme-Linked Immunosorbent Assay to Screen for Aflatoxins, Ochratoxin A, and Deoxynivalenol in Dry Pet Foods}

\section{Comments}

This is a pre-copy-editing, author-produced PDF of an article accepted for publication in Mycotoxin Research, volume 34, issue 1, in 2017 following peer review. The final publication is available at Springer via DOI: $10.1007 / \mathrm{s} 12550-017-0300-3$.

\section{Copyright}

Society for Mycotoxin Research and Springer-Verlag GmbH Germany 
1 Use of enzyme-linked immunosorbent assay to screen for aflatoxins, ochratoxin A, and

2 deoxynivalenol in dry pet foods

3

4 Authors: Tara A. Okuma ${ }^{\mathrm{a}}$, Thu P. Huynh ${ }^{\mathrm{b}}$, Rosalee S. Hellberga*

5

6 a Chapman University, Schmid College of Science and Technology, Food Science Program, One

7 University Drive, Orange, CA USA 92866

$8 \quad{ }^{b}$ Helica Biosystems, Inc., 3310 W. MacArthur Blvd., Santa Ana, CA USA 92704

9

10 *Corresponding author: Rosalee S. Hellberg, Phone: +1-714-628-2811, e-mail:

11 hellberg@chapman.edu

12 
14 The objective of this study was to perform a market survey on dry pet foods using

15 enzyme-linked immunosorbent assay (ELISA) to detect total aflatoxins (AFs), ochratoxin A

16 (OTA), and deoxynivalenol (DON). Pet food products $(\mathrm{n}=58)$ marketed for dogs, cats, birds,

17 and rabbits were tested in duplicate with ELISA and results above the limit of quantitation were

18 confirmed using liquid chromatography tandem mass spectrometry (LC-MS/MS). OTA was

19 detected in one product (rabbit food) and AFs were detected in two products (one dog treat and

20 one bird treat). In contrast, DON was detected in the majority (74\%) of products tested. Bird and

21 rabbit products were the most affected by DON, with levels above $0.5 \mu \mathrm{g} / \mathrm{g}$ in $50 \%$ and $80 \%$ of

22 samples, respectively. One rabbit sample tested positive for both OTA and DON. Overall, the

23 findings of this study revealed a low incidence of AFs and OTA in commercial pet food.

24 Although DON was detected in numerous products, the levels were well below those associated

25 with acute toxic effects.

27 Keywords: aflatoxins; deoxynivalenol; ELISA; mycotoxins; ochratoxin A; pet foods 
Introduction

Pets are a growing industry in the U.S., with \$28 billion spent on pet food alone in 2016 (APPA 2017). Domestic pets are particularly at-risk for illness from adulterated food because a

31 single type of pet food typically comprises the majority or sole component of a pet's diet

32 (Bischoff and Rumbeiha 2012). Many ingredients commonly used in pet foods, such as corn,

33 wheat, barley, soy, and peanuts, are susceptible to contamination with mycotoxins. Due to the

34 potential for detrimental health effects resulting from mycotoxin exposure, many countries have

35 developed regulations and guidelines for mycotoxins in animal feed, including feed intended for

36 pet animals ('pet food') (for example, EC 2002; EC 2006; FDA 2000; FDA 2010).

Between 1996 and 2016, the U.S. Food and Drug Administration (FDA) reported 11

38 recalls in the U.S. pertaining to the presence or potential presence of mycotoxins in pet foods

39 (FDA 2017; Rumbeiha and Morrison 2011). The majority of these recalls involved dog or cat

40 food associated with aflatoxins (AFs) or aflatoxin-producing mold. In 2005-2006, over 700,000

41 pet food packages distributed to 24 states in the U.S. and 30 other countries were recalled due to

42 aflatoxin contamination (FDA 2007; Rumbeiha and Morrison 2011). The contaminated pet foods

43 were associated with the death of at least 76 dogs and caused illnesses in an undetermined

44 number of animals. In South Africa, aflatoxin-contaminated dry dog food led to an aflatoxicosis

45 outbreak and was estimated to have caused over 200 fatalities (Arnot et al. 2012).

46 Globally, several mycotoxins have been detected in retail pet foods, including AFs,

47 ochratoxin A (OTA), and DON (Abd-Elhakim et al. 2016; Arnot et al. 2012; Blajet-Kosicka et

48 al. 2014; Böhm et al. 2010; Gazzotti et al. 2015; Henke et al. 2001; Pühringer et al. 2007;

49 Razzazi et al. 2001; Sharma and Marquez 2001; Songsermsakul et al. 2007). For instance, OTA

50 was detected in dog and cat foods purchased in Austria and Poland, with the highest level of 13.1 
$51 \mathrm{ng} / \mathrm{g}$ in a dry dog food sample and other positive samples containing 0.21-3.2 ng/g (Razzazi et al.

52 2001). In another study, DON was detected in $97 \%$ of Austrian dry dog food samples tested by

53 ELISA and $83 \%$ of a subset of samples confirmed with high-performance liquid chromatography

54 (HPLC) (Böhm et al. 2010). Henke et al. (2001) surveyed 142 bags of wild bird seeds purchased

55 in Texas, USA, and found that $17 \%$ of samples contained AFs at levels > $100 \mathrm{ng} / \mathrm{g}$.

56 Despite the potential for mycotoxin contamination in pet foods sold on the U.S.

57 commercial market, there is a lack of current research on this topic. There is also a paucity of

58 information regarding mycotoxin contamination of food marketed for smaller animals, such as

59 birds and rabbits, as the majority of studies have focused on dog food. Therefore, the objective of

60 this study was to perform a market survey of dry pet foods and treats marketed for dogs, cats,

61 rabbits, and birds to examine for contamination with AFs, OTA, and DON using enzyme-linked

62 immunosorbent assay (ELISA).

\section{Materials and Methods}

\section{Sample collection and preparation}

65 A total of 58 dry pet foods containing grain- and peanut-based ingredients were

66 purchased from six retail stores in Orange County, CA, USA. These samples consisted of food

67 and treats marketed for dogs, cats, birds, and rabbits (see Online Resource 1 for further details).

68 The products selected for this study represented 36 pet food brands and 28 manufacturers or

69 distributors. Following collection, the samples were cataloged, assigned a sample ID, and stored

70 at room temperature. For sample preparation, each pet food package was thoroughly mixed by

71 hand-agitation of the external packaging for one minute, then aseptically sampled. A portion of

72 each sample $(100 \pm 5 \mathrm{~g})$ was finely ground using an Oster ${ }^{\circledR}$ Blender base and sterilized Blend-N-

73 Go Smoothie Kit (Jarden Corporation, Rye, NY, USA) until 75\% or more of the sample passed 
74 through a $0.841 \mathrm{~mm}$ sieve (Helica 2014a; Helica 2014b; Neogen 2008). Ground and

75 homogenized samples were stored in sterile $50 \mathrm{~mL}$ conical centrifuge tubes (Corning, Inc.,

76 Corning, NY, USA) at $4^{\circ} \mathrm{C}$ until analysis.

77 ELISA verification for dry pet food screening

Pet foods were tested for AFs and OTA using the following ELISA kits from Helica

79 Biosystems, Inc. (Santa Ana, CA, USA): AFs low matrix kit for grains and cereal, silage, nuts,

80 spices, animal feed and OTA low matrix kit for coffee, cocoa, cocoa butter and spices. Because

81 these kits had not previously been verified by the manufacturer for use with dry pet foods, they

82 were subjected to spike-recovery testing prior to use in the market survey to ensure there were no

83 matrix interferences that would yield false results. The spike-recovery tests were carried out with

84 three dry pet food samples: dog food, bird food, and rabbit food. Dry dog food was used to

85 represent both dog and cat foods, as these foods typically contain similar types of ingredients.

86 The three samples were tested by spiking $0.50 \pm 0.05 \mathrm{~g}$ of ground samples with the target

87 mycotoxin at concentrations along the range of the standard curve supplied with each mycotoxin

88 kit. Mycotoxin stock solutions were acquired from Sigma-Aldrich (St. Louis, MO, USA) for

89 aflatoxin $\mathrm{B}_{1}\left(\mathrm{AFB}_{1}\right)$ and OTA. Each of the three pet food samples were spiked with 0.0, 1.0, 5.0,

90 and $20.0 \mathrm{ng} / \mathrm{g}$ of $\mathrm{AFB}_{1}$ and, separately, with $0.0,2.5,10.0,40.0 \mathrm{ng} / \mathrm{g}$ of OTA. Spiked samples

91 were left uncovered and dried overnight at room temperature in a SterilGARD ${ }^{\circledR}$ II Class II

92 biological safety cabinet (The Baker Company, Sanford, ME, USA) with the window sash

93 completely closed. Mycotoxin extraction and ELISA assays were performed the next day, as

94 described below. The kits were considered acceptable with mycotoxin recovery rates of 80-

$95120 \%$. The Veratox ${ }^{\circledR}$ DON 5/5 ELISA kits used in this study were previously validated for use 
96 with pet foods by Neogen Corporation (Lansing, MI, USA) and were not subjected to spike-

97 recovery testing in this study (Neogen 2013).

Mycotoxin extraction and ELISA screening

Mycotoxin extraction was performed on all ground pet food samples per the

manufacturers' specifications (Helica 2014a; Helica 2014b; Neogen 2008) with modifications to

101 the starting sample amount and volume of extraction solvent called for by the Helica kits.

102 Extractions for AFs and OTA were conducted using 0.5-1.0 g of ground sample mixed at a 1:5

103 ratio (w/v) with ACS grade acetonitrile (Fisher Scientific, Hampton, NH, USA) diluted to 80\%

104 with deionized water, while DON extractions were carried out with $10.0 \mathrm{~g}$ of ground sample

105 mixed at a 1:10 ratio with deionized water. AFs and OTA samples were vortexed for $10 \mathrm{~min}$ at

106 high speed, then centrifuged at $1370 \times \mathrm{g}$ for $10 \mathrm{~min}$. The supernatant extracts were diluted

107 according to the manufacturer's specifications with the kit-supplied wash buffer for AFs and

$10870 \%$ methanol (RICCA Chemical Company, Arlington, TX, USA) for OTA (Helica 2014a;

109 Helica 2014b). DON samples were vortexed at moderate speed for 5 min and left undisturbed at

110 room temperature for $3 \mathrm{~min}$. The supernatant extract was passed through filter syringes filled

111 with $1 \mathrm{~g}$ of chopped glass wool (Neogen Mycotoxin Extraction Kit). The $\mathrm{pH}$ of each sample

112 extract was determined and adjusted to a $\mathrm{pH}$ range of $6.0-8.0$ according to the manufacturer's

113 instructions using ACS grade 1.0 mol/L sodium hydroxide solution (Sigma-Aldrich) (Neogen

114 2008; Neogen 2013).

115 ELISA was performed on all sample extracts per the manufacturers' specifications using

116 the kits mentioned above for AFs, OTA, and DON. The extract from each sample was tested in

117 duplicate microplate wells using ELISA. Absorbance was measured at $450 \mathrm{~nm}$ for the AFs and

118 OTA ELISAs and at $650 \mathrm{~nm}$ for the DON ELISAs using a SpectraMax M2e multi-mode 
119 microplate reader (Molecular Devices, Sunnyvale, CA, USA) and SoftMax ${ }^{\circledR}$ Pro, version 6.4

120 software with 4-parameter logistic (4PL) curve fit. Pet food samples were considered to contain

121 detectable levels of AFs, OTA, and/or DON if the average results exceeded the minimum

122 detection limit of the respective assay. The detection limits of the AFs and OTA kits were

123 determined during spike-recovery testing to be $0.02 \mathrm{ng} / \mathrm{g}$ and $0.05 \mathrm{ng} / \mathrm{g}$, respectively. According

124 to the manufacturer, the detection limit of the DON kit was $0.1 \mu \mathrm{g} / \mathrm{g}$ and the limit of quantitation

125 (LOQ) was $0.5 \mu \mathrm{g} / \mathrm{g}($ Neogen 2008).

LC-MS/MS confirmation of quantifiable DON samples

Samples found to be above the LOQ for DON $(0.5 \mu \mathrm{g} / \mathrm{g})$ were submitted to Eurofins

128 Scientific (Garden Grove, CA, USA) for confirmation with liquid chromatography coupled with

129 tandem mass spectrometry (LC-MS/MS). Samples (25 g) were extracted and purified according

130 to the MultiSep ${ }^{\circledR} 226$ protocol (Romer Labs, (Getzersdorf, Austria). Chromatographic separation

131 for DON was performed with a Shimadzu Nexera x2 (Kyoto, Japan) with a SCIEX Triple Quad

1325500 (Framingham, MA, USA). A Thermo Scientific ${ }^{\mathrm{TM}}$ Acclaim ${ }^{\mathrm{TM}} 120 \AA ̊, \mathrm{C} 18,2.2 \mu \mathrm{m}$ column

133 (Waltham, MA, USA) was used with an injection volume of $5.0 \mu \mathrm{L}$. Mobile phase A consisted

134 of $0.1 \%$ acetic acid in $10 \%$ methanol/90\% water and mobile phase B consisted of $0.1 \%$ acetic

135 acid and $5 \mathrm{mmol} / \mathrm{L}$ ammonium acetate in $45 \%$ methanol $/ 45 \%$ acetonitrile/10\% water. A flow rate

136 of $0.400 \mathrm{~mL} / \mathrm{min}$ at $35^{\circ} \mathrm{C}$ was used with a gradient elution of $10 \% \mathrm{~B}$ for $3 \mathrm{~min}, 10-70 \% \mathrm{~B}$ from 3

137 to $7 \mathrm{~min}$, increased to $90 \% \mathrm{~B}$ in $0.1 \mathrm{~min}$, and then held at $90 \% \mathrm{~B}$ for $2 \mathrm{~min}$, followed by re-

138 equilibration for $3 \mathrm{~min}$ at 10\% B. MS/MS was performed with an electrospray ionization (ESI)

139 source in multiple reaction monitoring (MRM) mode. Ion source parameters for ESI+ were:

140 spray voltage of $4500 \mathrm{~V}$, curtain gas at $30 \mathrm{PSI}(207 \mathrm{kPa})$, gas source 1 at $60 \mathrm{PSI}$, gas source 2 at

$14180 \mathrm{PSI}$, and collision gas at $12 \mathrm{PSI}$, with a temperature of $550^{\circ} \mathrm{C}$. 
143 The results of the 16 samples quantified with DON ELISA were compared to the results

144 of the same samples tested with LC-MS/MS using a Wilcoxon signed-rank test, with a pre-

145 determined level of significance of $p<0.05$, two-tailed. Statistical analysis was carried out using

146 IBM SPSS Statistics 23 (Armonk, NY, USA).

\section{Results and Discussion}

148 ELISA verification results

149 Mean recoveries for mycotoxins in the spiked samples were within the predetermined 150 acceptable range of $80-120 \%$ for pet food samples tested with the AFs and OTA ELISA kits 151 (Table 1). The mean recoveries were 87.4-110.4\% for the AFs kit and 96.6-118.5\% for the OTA

152 kit. Recovery levels were similar across the three different matrices, with a coefficient of 153 variation (CV) under 20.0\% for all spike levels. Evaporation of the extract solvent can

154 concentrate the samples, resulting in $>100 \%$ recovery (Scudamore et al. 1997). Recoveries may 155 also be affected due to cross-reacting antibodies, matrix interference, and/or the presence of 156 masked mycotoxins (Berthiller et al. 2013; De Saeger et al. 2016; Rahmani et al. 2009; Tangni et 157 al. 2011). The recoveries obtained in this study were consistent with the typical recoveries 158 achieved in previous studies using methods such as ELISA, thin layer chromatography (TLC), 159 and HPLC (Maia and de Siqueira 2002; Scudamore et al. 1997; Urusov et al. 2015).

160 ELISA screening for mycotoxins in dry pet food

161 Of the 58 pet food samples tested in this study, 45 had detectable levels of AFs, OTA, or 162 DON, with both DON and OTA being detected in one sample (Table 2). OTA had the lowest 163 incidence rate $(1.7 \%)$, with detection in one sample of rabbit food containing soy and wheat- 
164 based ingredients as three of the first four ingredients listed. However, other rabbit food products

165 containing predominantly soy and wheat-based ingredients did not test positive for OTA,

166 indicating that this may be an isolated incident. The estimated level of OTA in the rabbit food

167 product was $2.6 \mathrm{ng} / \mathrm{g}$, based on ELISA testing. While the FDA has not established limits for

168 OTA in animal feed, the European Commission has a guidance value of $25 \mathrm{ng} / \mathrm{g}$ for OTA in

169 cereals and cereal products used in feed (EC 2006).

170

Similar to the OTA results, the incidence of AFs was low, at 3.4\%, with detection in just

171 two samples (Table 2). The main suspect ingredients in the two samples were peanut butter (dog

172 treat) and peanuts (bird treat). Both ingredients were the first of only four or five ingredients

173 listed on the label. While other pet food samples containing peanuts or peanut butter were below

174 the detection limit for AFs $(0.02 \mathrm{ng} / \mathrm{g})$, these components were further down on the ingredient

175 list. The estimated levels of aflatoxin for the two products in this study were $1.5 \mathrm{ng} / \mathrm{g}$ (bird treat)

176 and $12.3 \mathrm{ng} / \mathrm{g}$ (dog treat). These levels are below the FDA action level of $20 \mathrm{ng} / \mathrm{g}$ for aflatoxin in

177 animal feed ingredients intended for the products tested in this study (FDA 2000) and below the

178 European Commission maximum allowed levels of $\mathrm{AFB}_{1}$ in feed materials $(20 \mathrm{ng} / \mathrm{g})$. The dog

179 treat was above the European Commission maximum level for $\mathrm{AFB}_{1}$ in complete feedingstuffs

$180(10 \mathrm{ng} / \mathrm{g})$ applicable to the products tested in this study; however, the assay used in the current

181 study measured total AFs and did not differentiate $\mathrm{AFB}_{1}$ from other aflatoxins (EC 2002).

182 As compared to the AFs and OTA results, the incidence rate for DON in pet food was

183 much higher, at $74.1 \%$, with bird and rabbit products being the most affected (Table 2). The high

184 incidence of detectable DON is similar to that found by previous studies conducted in Austria,

185 Italy, and Poland, which reported the presence of DON in 83-100\% of the dry dog and/or cat

186 food samples tested (Blajet-Kosicka et al. 2014; Böhm et al. 2010; Gazzotti et al. 2015). Of the 
18743 samples in this study with detectable DON levels $(\geq 0.1 \mu \mathrm{g} / \mathrm{g}), 27$ products were below the 188 LOQ $(0.5 \mu \mathrm{g} / \mathrm{g})$ and 16 products were above the LOQ, with the highest ELISA result at $1.6 \mu \mathrm{g} / \mathrm{g}$

189 for a rabbit treat (Online Resource 1). The 16 products with quantifiable levels were further

190 tested with LC-MS/MS for confirmation, as discussed in the following section. The FDA

191 advisory level for DON is $5 \mu \mathrm{g} / \mathrm{g}$ in grains and grain by-products for animals other than cattle

192 and chickens, with a recommendation that DON-contaminated ingredients make up less than 20-

$19340 \%$ of the diet, depending on the animal (FDA 2010). Similarly, the European Commission has

194 a guidance value of $5 \mu \mathrm{g} / \mathrm{g}$ for DON in complete feedingstuffs (EC 2006).

195 The only sample in the current study with detectable levels of multiple mycotoxins was a 196 rabbit food product containing both OTA and DON (Table 2). OTA was estimated to be present

197 at a level of $2.6 \mathrm{ng} / \mathrm{g}$ and DON was quantified at $<1.0 \mu \mathrm{g} / \mathrm{g}$. The co-contamination of

198 mycotoxins in crops has been previously reported and more research on the additive and

199 synergistic effects is needed (Kovalsky et al. 2016; Smith et al. 2016).

200 Confirmation of quantifiable DON with LC-MS/MS analysis

The 16 pet food samples with DON levels above the LOQ $(0.5 \mu \mathrm{g} / \mathrm{g})$ for the ELISA kit

202 were confirmed using LC-MS/MS (Fig. 1). The average quantifiable DON level for the 16

203 samples tested by ELISA was $0.9 \mu \mathrm{g} / \mathrm{g}$ with a range of $0.6-1.6 \mu \mathrm{g} / \mathrm{g}$, and the average LC-

204 MS/MS result was $0.6 \mu \mathrm{g} / \mathrm{g}$ with a range of $0.1-1.0 \mu \mathrm{g} / \mathrm{g}$. When the levels determined for these

20516 samples were compared statistically, the results of ELISA were significantly higher than the

206 results of LC-MS/MS, based on a Wilcoxon signed-rank test ( $p<0.05$, two-tailed). This may

207 have been due to cross-reactivity of the ELISA antibodies with related compounds (Tangni et al.

208 2010). The results of LC-MS/MS and ELISA were correlated, with an R-squared value of 0.82 
209 (Fig. 1), suggesting that ELISA may be used as a screening method for DON in dry pet foods.

210 However, testing with LC-MS/MS is recommended in order to verify quantitative results.

211 Among the 16 samples with quantifiable DON levels, products marketed for rabbits

212 (50\%) and birds (25\%) were the most affected, followed by dogs (19\%) and cats (6\%). When

213 considering potential sources of DON in the products, wheat-based ingredients were found in the

214 greatest number of products, followed by ingredients containing corn, soy, and oats (Online

215 Resource 1). The presence of DON in foods containing a high proportion of grain ingredients is

216 consistent with the results of the 2016 mycotoxin survey of animal feed commodities, where

217 DON was found in $85 \%$ of finished feed samples, $73 \%$ of corn samples and $70 \%$ of cereal grain

218 samples (wheat, barley, and oats) tested within North America (Biomin 2017). The levels of

219 DON detected in this study are similar to the findings of Austrian studies on dry dog food, which

220 reported average levels of 0.41-0.48 $\mu \mathrm{g} / \mathrm{g}$ (Böhm et al. 2010; Songsermsakul et al. 2007).

221 The levels of DON detected in this study were well below those that cause acute toxicity

222 symptoms (i.e., vomiting) in dogs and cats, which have been reported to be $8 \mu \mathrm{g} / \mathrm{g}$ and $10 \mu \mathrm{g} / \mathrm{g}$,

223 respectively (Hughes et al. 1999). However, prolonged exposure to lower levels of DON may

224 contribute to chronic toxic effects, such as loss of appetite, weight loss, and nutritional

225 deficiencies (Pestka 2007). Although these effects have not been widely studied in cats or dogs,

226 studies on other animals have found partial feed refusal in pigs exposed to levels as low as 1-2

$227 \mu \mathrm{g} / \mathrm{g}$ and significant body weight reduction in mice fed $5 \mu \mathrm{g} / \mathrm{g}$ DON over a period of 2 years.

228 Overall, the results of this study indicate a low incidence of AFs and OTA in dry pet

229 foods sold on the U.S. commercial market. Although DON was frequently detected in these

230 foods, the results were well below regulatory limits and would not be expected to cause acute

231 health effects. However, there remains a risk of chronic low-level exposure to mycotoxins in pet 
232 food due to the focused consumption pattern of these animals. In this study, ELISA served as a

233 rapid and reliable screening method for the detection of mycotoxins in dry pet foods.

234 Furthermore, ELISA and LC-MS/MS methods for quantifying DON in dry pet foods were

235 correlated. Due to the potential health risks of chronic exposure to mycotoxins, regular screening

236 of pet foods is recommended and pets should be carefully monitored for symptoms of exposure.

237 Source of Funding

238 This work was supported by internal funding from Chapman University Schmid College of

239 Science and Technology. Helica Biosystems, Inc. donated the Total Aflatoxins and Ochratoxin A

240 ELISA kits used in this study. The funding sources had no role in the design of the study; in the

241 collection, analyses, or interpretation of data; in the writing of the manuscript; or in the decision

242 to publish the results.

243 Acknowledgements

244 The authors would like to thank the following individuals for their assistance: Brittany Zavala,

245 Brenda Hernandez, Glenn Woerndle, Jason Keller, Ph.D., and Lilian Were, Ph.D.

246 Conflicts of Interest

247 T.P. Huynh is employed by Helica Biosystems, Inc.; T.A. Okuma was formerly employed by

248 Helica Biosystems.

249 Ethical Standards

250 These experiments comply with the current laws of the United States of America.

$251 \quad$ References

252 Abd-Elhakim YM, El Sharkawy NI, Moustafa GG (2016) An investigation of selected chemical 253 contaminants in commercial pet foods in Egypt. J Vet Diagn Invest 28:70-75 
254 APPA (2017) Pet industry market size and ownership statistics. American Pet Products

255 Association. http://www.americanpetproducts.org/press_industrytrends.asp. Accessed

$256 \quad$ July 14,2017

257 Arnot LF, Duncan NM, Coetzer H, Botha CJ (2012) An outbreak of canine aflatoxicosis in

258 Gauteng Province, South Africa. J S Afr Vet Assoc 83:2-6

259 Berthiller F et al. (2013) Masked mycotoxins: A review. Mol Nutr Food Res 57:165-186

260 Biomin (2017) World mycotoxin survey 2016 annual report.

261 https://info.biomin.net/acton/attachment/14109/f-0463/1/-/-/1-0009/1-

262 0009:5457/MAG_MTXsurveyReport_2016_EN_0117_PKO.pdf. Accessed July 15, 2017

263 Bischoff K, Rumbeiha WK (2012) Pet food recalls and pet food contaminants in small animals.

264 Vet Clin North Am Small Anim Pract 42:237-250

265 Blajet-Kosicka A, Kosicki R, Twaruzek M, Grajewski J (2014) Determination of moulds and

266 mycotoxins in dry dog and cat food using liquid chromatography with mass spectrometry

267 and fluorescence detection. Food Addit Contam Part B 7:302-308

268 Böhm J, Koinig L, Razzazi-Fazeli E, Blajet-Kosicka A, Twaruzek M, Grajewski J, Lang C

269 (2010) Survey and risk assessment of the mycotoxins deoxynivalenol, zearalenone,

270 fumonisins, ochratoxin A, and aflatoxins in commercial dry dog food. Mycotoxin Res

$271 \quad 26: 147-153$

272 De Saeger S, Audenaert K, Croubels S (2016) Report from the 5th International Symposium on

273 mycotoxins and toxigenic moulds: Challenges and perspectives (MYTOX) held in Ghent,

274 Belgium, May 2016. Toxins 8:146-183 
275 EC (2002) European Commission (EC). Directive 2002/32/EC of the European Parliament and 276 of the Council on undesirable substances in animal feed. Official Journal of the European $277 \quad$ Union L 140:10-22

278 EC (2006) European Commission (EC). Commission Recommendation (2006/576/EC) of 17 August 2006 on the presence of deoxynivalenol, zearalenone, ochratoxin A, T-2 and HT2 and fumonisins in products intended for animal feeding. Official Journal of the European Union L 229:7-9

FDA (2000) Guidance for industry: Action levels for poisonous or deleterious substances in human food and animal feed. U.S. Food and Drug Administration. https://www.fda.gov/Food/GuidanceRegulation/GuidanceDocumentsRegulatoryInformati on/ChemicalContaminantsMetalsNaturalToxinsPesticides/ucm077969.htm. Accessed August 2, 2017

FDA (2007) The enforcement story 2006. U.S. Food and Drug Administration. http://www.fda.gov/ICECI/EnforcementActions/EnforcementStory/EnforcementStoryArc hive/ucm090818.htm. Accessed July 15, 2017

FDA (2010) Guidance for industry: Advisory levels for deoxynivalenol (DON) in finished wheat products for human consumption and grains and grain by-products used for animal feed. U.S. Food and Drug Administration. http://www.fda.gov/Food/GuidanceRegulation/GuidanceDocumentsRegulatoryInformati on/ChemicalContaminantsMetalsNaturalToxinsPesticides/ucm120184.htm. Accessed July 14, 2017 
FDA (2017) Archive for recalls, market withdrawals, and safety alerts. U.S. Food and Drug Administration. https://www.fda.gov/safety/recalls/archiverecalls/default.htm. Accessed July 15,2017

Gazzotti T, Biagi G, Pagliuca G, Pinna C, Scardilli M, Grandi M, Zaghini G (2015) Occurrence of mycotoxins in extruded commercial dog food. Anim Feed Sci Technol 202:81-89 Helica (2014a) Ochratoxin A in Coffee, Cocoa, and Spices - Quantitative Assay Kit Insert. Helica Biosystems, Inc., Santa Ana, CA.

Helica (2014b) Total Aflatoxin Assay - Low Matrix Kit Insert. Helica Biosystems, Inc., Santa Ana, CA.

Henke SE, Gallardo VC, Martinez B, Balley R (2001) Survey of aflatoxin concentrations in wild bird seed purchased in Texas. J Wildl Dis 37:831-835

Hughes DM, Gahl MJ, Graham CH, Grieb SL (1999) Overt signs of toxicity to dogs and cats of dietary deoxynivalenol. J Anim Sci 77:693-700

Kovalsky P et al. (2016) Co-occurrence of regulated, masked and emerging mycotoxins and secondary metabolites in finished feed and maize—An extensive survey. Toxins 8:363

313 Neogen (2008) Veratox 5/5 Quantitative DON Test Kit Insert. Neogen Corporation, Lansing, MI.

315 Neogen (2013) Mycotoxin handbook. Neogen Corporation, Lansing, MI, p. FD107-0113.

316 Pestka JJ (2007) Deoxynivalenol: Toxicity, mechanisms and animal health risks. Anim Feed Sci 317 Technol 137:283-298 
318 Pühringer S, Razzazi-Fazeli E, Kübber-Heiss A, Böhm J, Iben C (2007) Occurrence of

319 ochratoxin A in feline kidneys and pet foods for cats. Wiener Tierärztliche Monatsschrift 94:192-196

321 Rahmani A, Jinap S, Soleimany F (2009) Qualitative and quantitative analysis of mycotoxins. Compr Rev Food Sci Food Saf 8:202-251

Razzazi E, Böhm J, Grajewski J, Szczepaniak K, Kübber-Heiss AJ, Iben CH (2001) Residues of 325 ochratoxin A in pet foods, canine and feline kidneys. J Anim Physiol Anim Nutr 85:212216

Rumbeiha W, Morrison J (2011) A review of class I and class II pet food recalls involving chemical contaminants from 1996 to 2008. J Med Toxicol 7:60-66

Scudamore KA, Hetmanski MT, Nawaz S, Naylor J, Rainbird S (1997) Determination of mycotoxins in pet foods sold for domestic pets and wild birds using linked-column immunoassay clean-up and HPLC. Food Addit Contam Part A 14:175-186

Sharma M, Marquez C (2001) Determination of aflatoxins in domestic pet foods (dog and cat) using immunoaffinity column and HPLC. Anim Feed Sci Technol 93:109-114

Smith M-C, Madec S, Coton E, Hymery N (2016) Natural co-occurrence of mycotoxins in foods and feeds and their in vitro combined toxicological effects. Toxins 8:94-130 Deoxynivalenol loads in matched pair wheat samples in Belgium: comparison of ELISA Veratox kit against liquid chromatography. Mycotoxin Res 27:105-113 
340 Tangni EK, Motte JC, Callebaut A, Pussemier L (2010) Cross-reactivity of antibodies in some commercial deoxynivalenol test kits against some fusariotoxins. J Agric Food Chem $58: 12625-12633$

343 Urusov AE, Zherdev AV, Petrakova AV, Sadykhov EG, Koroleva OV, Dzantiev BB (2015) 


\section{$363 \quad$ Figure caption}

364 Figure 1 Comparison of DON quantitation results based on testing with ELISA and LC-MS/MS 
Table 1 Recoveries of $\mathrm{AFB}_{1}$ and OTA using ELISA with spiked pet food samples. The detection limits were determined to be $0.02 \mathrm{ng} / \mathrm{g}$ for AFs and $0.05 \mathrm{ng} / \mathrm{g}$ for OTA.

\begin{tabular}{lcccc}
\hline Mycotoxin & $\begin{array}{c}\text { Spike Level } \\
(\mathrm{ng} / \mathrm{g})\end{array}$ & $\begin{array}{c}\text { Mean Recovery } \\
(\mathrm{ng} / \mathrm{g})\end{array}$ & $\begin{array}{c}\text { Standard } \\
\text { Deviation of } \\
\text { Recovery }^{\mathrm{a}}\end{array}$ & Mean \% Recovery \\
\hline AFB $_{1}$ & 20.00 & 21.93 & 0.91 & 109.6 \\
& 5.00 & 4.37 & 0.09 & 87.4 \\
OTA & 1.00 & N/A & 0.11 & 110.4 \\
& 0.00 & 39.13 & N/A & N/A \\
& 40.00 & 9.66 & 6.46 & 97.8 \\
& 10.00 & 2.96 & 0.73 & 96.6 \\
& 2.50 & N/A & 0.58 & 118.5 \\
\hline
\end{tabular}

${ }^{a}$ Based on combined results for three spiked pet foods (dog, rabbit, and bird) tested with ELISA in duplicate. 
Table 2 Summary of mycotoxin detections resulting from ELISA testing of dry pet food samples $(n=58)$, based on detection limits of $0.02 \mathrm{ng} / \mathrm{g}$ for AFs, $0.05 \mathrm{ng} / \mathrm{g}$ for OTA, and $0.1 \mu \mathrm{g} / \mathrm{g}$ for DON.

\begin{tabular}{lcccc}
\hline \multirow{2}{*}{ Pet food type } & $\begin{array}{c}\text { Number of } \\
\text { samples } \\
\text { collected }\end{array}$ & OTA & AFs & DON \\
\cline { 3 - 5 } Dog food & 9 & 0 & 0 & 6 \\
Dog treats & 10 & 0 & 1 & 6 \\
Cat food & 9 & 0 & 0 & 8 \\
Cat treats & 10 & 0 & 0 & 5 \\
Bird food & 6 & 0 & 0 & 5 \\
Bird treats & 4 & 0 & 1 & 3 \\
Rabbit food & 7 & $1^{\mathrm{a}}$ & 0 & 7 \\
Rabbit treats & 3 & 0 & 0 & 3 \\
\hline Overall & $\mathbf{5 8}$ & $\mathbf{1}$ & $\mathbf{2}$ & $\mathbf{4 3}$ \\
\hline
\end{tabular}

${ }^{\bar{a}}$ One sample of rabbit food contained detectable levels of both OTA and DON 